\title{
The Use of Respondent-Driven Sampling To Assess Febrile Illness Treatment-Seeking Behaviors Among Forest Goers in Cambodia and Vietnam
}

\section{Mahesh Paudel}

Population Services International

Kemi Tesfazghi ( $\sim$ ktesfazghi@psi.org)

Population Services International https://orcid.org/0000-0001-9202-4517

Hoa Nguyen

Population Services International

Sochea Phok

Population Services International

\section{Shwetha Srinivasan}

Population Services International

Jennifer Wheeler

Population Services International

\section{Research}

Keywords: illness, forest goers, GMS, malaria

Posted Date: July 27th, 2021

DOI: https://doi.org/10.21203/rs.3.rs-715059/v1

License: (c) (i) This work is licensed under a Creative Commons Attribution 4.0 International License. Read Full License 


\section{Abstract \\ Background}

Countries in the Greater Mekong Subregion (GMS) aim to eliminate all forms of malaria by 2030 . In Cambodia and Vietnam Forest goers are at highest risk of malaria. Universal access to prompt diagnosis and treatment is a core malaria intervention. This can only be achieved by understanding the health seeking behaviors among the most vulnerable groups and eliminating the barriers to prompt and effective treatment. This study aimed to improve understanding by exploring health seeking behaviors for febrile illness among populations at risk for malaria in Cambodia and Vietnam.

\section{Methods}

In 2019, researchers from Population Services International (PSI) conducted a population-based survey of forest goers in Cambodia and Vietnam using respondent-driven sampling (RDS). In Cambodia two operational districts, Oral and Phnom Srouch, in Kampong Speu Province were included in the study. In Vietnam, communes located within $15 \mathrm{~km}$ of the forest edge in Binh Phuoc and Gia Lai provinces were selected. Adults who had spent at least one night per week or four nights per month in the forest over the past three months were considered potential participants for the study.

\section{Results}

$75 \%$ in Cambodia and $65 \%$ in Viet Nam of forest goers sought treatment outside the home for illness. In Cambodia $39 \%$ sought treatment from the private sector, $32 \%$, from community health workers and $24 \%$ from public health facilities. In Vietnam, $62 \%$ sought care from community facilities, $29.3 \%$ from the private sector and $6.9 \%$ went to a public facility. Amongst forest goers who sought care, $33 \%$ in Cambodia and $52 \%$ in Vietnam did so within 24 hours.

\section{Conclusions}

This study is consistent with others that show that early diagnosis and treatment of malaria remains an obstacle to malaria elimination. This study also demonstrates that there are gaps in timeliness of care seeking amongst forest goers. The findings from this study around provider preference and delays in treatment seeking behaviors can be utilized to strengthen the design and targeting of malaria interventions and social behavior change strategies in order to accelerate malaria elimination in Cambodia and Vietnam.

\section{Background}


Substantial progress has been made towards malaria elimination in the Greater Mekong Subregion (GMS) where countries are working towards elimination of all forms of malaria by 2030 . The number of reported malaria case declined by $86 \%$ and the number of malaria related deaths declined by $97 \%$ between 2010 and 2019 (1, 2). According to WHO, the GMS shows a 47\% decline in malaria cases from 2019 to 2020. Plasmodium falciparum cases no longer comprise the majority of cases in the subregion as Plasmodium falciparum accounted for $32 \%$ of all cases in 2019 (compared to $80 \%$ of all cases in 2012). Increased funding and improved vector control, testing and treatment mechanisms have led to a significant decline in cases.

Malaria in Cambodia and Vietnam most often occurs in forest and forest-fringe areas. Individuals living or working near the forest have a higher risk of malaria incidence than people who live further from the forest (1). In Vietnam, approximately $60 \%$ of reported malaria cases are from individuals sleeping in forests or on farms (3). Malaria transmission in Vietnam is highly focused along the hilly and forested regions of southern and central provinces along the Laos and Cambodian border where the population is engaged in forest related activities (4-7). In Cambodia, a population movement framework (PMF) for malaria was developed(8). The PMF identified forest workers as having the highest exposure to malaria and lowest access to services, mainly because of their proximity to forests, sub-optimum housing/sleeping conditions (hammock out in open spaces or in tents or makeshift shelters), low prevention practices, remoteness with respect to health services, mobility and disassociation with existing community mechanisms for the delivery of interventions or services (8-10).

The malaria case distribution in both countries demonstrates geographical heterogeneity and continues to disproportionately affect forest workers, population living in forest fringed areas and migrants. There is high population movement within and between countries in the GMS, often driven by poverty, population growth, unemployment, and political oppression $(8,10,11)$. In Cambodia and Vietnam, forest goers are a key target group for malaria elimination efforts (12).

The WHO Global Technical Strategy calls for ensuring universal access to malaria prevention, diagnosis and treatment as a fundamental pillar of achieving malaria elimination (13). Despite steep declines in malaria cases, both countries still require significant effort to achieve their malaria elimination goals ( 2 , 4). Securing access to early diagnosis (usually with in 24 hours of the onset of symptoms) and treatment for forest goers is critical (12). Since the Alma Ata Declaration in 1978, international efforts to improve access to primary health care have focused on strengthening community health worker (CHWs) programs. Community-based interventions by $\mathrm{CHWs}$ have successfully improved access to early malaria case detection and treatment (14).

In Vietnam, Village Health Workers (VHWs) are the backbone of the community-level health response in Vietnam. Although not full-time employee of the government, VHWs receive an allowance to engage in outreach activities, mainly focused on health promotion and prevention. In Cambodia, the village malaria worker (VMW) initiative was launched by the National Center for Parasitology, Entomology and Malaria Control (CNM) in 2004 to expand access to early malaria diagnosis and treatment for communities in 
remote villages where access to health care may be compromised by geographic and economic barriers $(15,16)$. In 2009 , the VMW cadre was expanded to include mobile malaria workers (MMWs) to target remote populations with active case detection approaches (17).

While efforts to train and deploy health personnel are an important element of ensuring availability of services, ensuring universal access to diagnosis and treatment services can only be achieved by understanding health seeking behaviors among the most vulnerable groups and eliminating the barriers they face throughout their journeys.

The objective of this study was to improve understanding by exploring health seeking journeys for febrile illness among populations at risk for malaria in Cambodia and Vietnam. The results of this study will offer evidence that informs malaria elimination interventions that can be better targeted towards forest goers most at risk of malaria.

\section{Methods}

Due to forest goers' hard-to-reach and often mobile status, novel data collection methods are required to gain behavioral insights from this group to inform appropriate malaria elimination interventions. In Cambodia and Vietnam, this group is 'hidden' from the general population in order to avoid detection by law enforcement that regulate forest exploration. In 2019 researchers from Population Services International (PSI) conducted a population-based survey of forest goers in Cambodia and Vietnam using respondent-driven sampling (RDS). RDS is a modified form of the snowball or chain referral sampling approach used to sample hard-to-reach or hidden populations who are linked through their social networks in situations where a sampling frame is difficult to obtain (18-21). The approach uses initial study participants or "seeds" to recruit peers from their social networks. The initial bias created by the non-probability-based selection is overcome by the use of mathematical modeling and assumptions that allow for inferences to be made about the sampled population (18-21).

\subsection{Study Population}

In Cambodia two operational districts, Oral and Phnom Srouch, in Kampong Speu Province were selected. Within these districts, 63 villages were grouped into 21 clusters based on their geo-position and proximity to each other. These districts were selected due to the high incidence of malaria, proximity to the forest and ease of access to forest goers. In Vietnam, communes located within $15 \mathrm{~km}$ of the forest edge in Binh Phuoc and Gia Lai provinces were selected for the study. Since Vietnam did not have an official definition of forest goers, for this study forest goers in Vietnam were defined as people who live inside or within $15 \mathrm{~km}$ of the forest and go into the forest at least one night a week or two nights a month.

Male and female ages 18 years and above who spent at least one night per week or four nights per month in the forest over the past 3 months were considered potential participants for the study. The criteria for inclusion in Cambodia also included having fever in the last 30 days. Forest goers meeting 
these criteria and either producing a coupon or selected as a seed were included in the study. Those not consenting to the study or not having coupon were not included in the study.

\subsection{Sampling and forest goer recruitment}

Given the nature of the target population, a clear sampling frame was not available. In both countries, the sample sizes were calculated using a conservative proportion for the main outcome of $50 \%$ with a confidence level of $95 \%$ and margin of error of $5 \%$. The design effect was set at 2.0. A sample size of 675 participants for each of the countries was required for the survey. Sample sizes were calculated separately for Cambodia forest goers and Vietnam forest goers with an assumption that the social network of the forest goers in two countries are independent of each other.

The initial seeds were purposefully selected based on criteria established at the start of the study. The seeds were selected with help from key informants, including the community leaders, to ensure they were representative of the forest goers and were well known and had a good social network. Seeds were provided with uniquely coded coupons (three in Cambodia and five in Vietnam) and asked to recruit subsequent study participants meeting the criteria from within their networks (Fig. 1). The first set of recruits are known as the first wave. The first wave is asked to recruit peers-the second wave-and so on until the estimated sample size is reached.

\subsection{Data collection and management}

In both countries, the data collection team was divided into four groups with two data collectors per group. The data collectors were trained on the consent process, coupons tracking incentives management, as well as the questionnaire and interview process. The data collectors used a tracking form to track the coupons, manage the incentives to the respondents and track the total number of interviews conducted each day. This form was sent to the field manager, who was responsible for overall recruitment.

The study questionnaire was translated into Khmer and Vietnamese for respective countries and included sections on basic demographics, forest going frequency and purpose, knowledge and availability of health services within the proximate community, preferences for health service providers, information regarding the most recent fever episode, health care seeking, behavior, and knowledge of malaria transmission. The questionnaire was administered using SurveyCTO in Cambodia and SurveyTOGO in Vietnam, that had built-in checks for data quality. The forms were submitted to a central server at the end of each day. Both the research team and field manager conducted onsite data quality checks.

\subsection{Data Analysis}

Data analysis was performed using the RDS function in Stata 15. Population weights were generated for each variable of interest to control for the for differences in social network size and homophily of the estimates. The social network size was defined as the number of forest goers that the participant knew who were 18 years and over, lived in the same community, and had spent at least one night per week or 4 nights per month in forest. Chi-square test were performed to check the relationship between health 
seeking behavior and the other variables. Multivariant logistic regression was conducted to understand association between type of health facility and reasons for preferences. Each reason for preference were dummy coded as an independent variable for the analysis. All analyses were separately performed for the two countries.

\subsection{Ethical consideration}

The study design and protocols for the study were reviewed and approved by the PSI Ethics Board, the National Ethics Committee for Health Research for Cambodia, and the Hanoi School of Public Health Ethics Board for Vietnam. Informed consent was obtained from participants prior to enrollment in the study.

\section{Results}

\subsection{Recruitment}

Among Cambodian forest goers, 21 initial seeds recruited 654 study participants over 3-6 waves of recruitment. In Vietnam, 15 initial seeds recruited 633 study participants over 3-5 waves of recruitment. In both countries $90 \%$ of coupons were returned.

All participants had spent a night in forest in the last one week or at least four nights per month in the last three months. Most participants were recruited by their friends (Cambodia 96.9\% and Vietnam 92.3\%) who they had known for more than a year (Cambodia $91.6 \%$ and Vietnam 79.3\%). The forest goers in Cambodia reported knowing fewer forest goers compared to Vietnam, with $40 \%$ of forest goers in Cambodia knowing five or fewer, while $48.9 \%$ of forest goers in Vietnam knew 10 or more other forest goers. Table 1 shows the unweighted analysis of recruitment patterns in Cambodia and Vietnam. 
Table 1

Unweighted Analysis of Recruitment Patterns

\begin{tabular}{|lll|}
\hline & Cambodia & Vietnam \\
\hline & $\begin{array}{l}\text { Unweighted Proportion } \\
(\mathbf{N}=\mathbf{6 7 5})\end{array}$ & $\begin{array}{l}\text { Unweighted Proportion } \\
(\mathbf{N}=648)\end{array}$ \\
\hline Reasons for Participation & & \\
\hline Interested in study topic & 57.8 & 28.2 \\
\hline Wanted to help the community & 14.1 & 59.7 \\
\hline My friend wanted me to participate & 25.0 & 1.4 \\
\hline Incentive/gift & 3.0 & 10.7 \\
\hline Others & 0.2 & - \\
\hline Known the person & & \\
\hline$<6$ months & 4.4 & 11.4 \\
\hline 6-12 months & 0.9 & 1.9 \\
\hline More than a year & 91.6 & 79.3 \\
\hline Missing & 3.1 & 7.4 \\
\hline Number of other forest goers known & & 21.04 \\
\hline Five or less & 40.0 & 26.1 \\
\hline 6 to 10 & 34.5 & 48.9 \\
\hline More than 10 & 25.5 & 0.9 \\
\hline Don't know & - & 2.04 \\
\hline Mean & & \\
\hline & & \\
\hline
\end{tabular}

\subsection{Demographics}

The majority of the forest goers in Cambodia were married (84.3\%), male (85.5\%), less than 40 years years $(73.2 \%)$, and had completed primary level education (47.8\%). Almost $80 \%$ of the forest goers earned their living through forest related work but made very little with $95.4 \%$ earning less than USD 500 per month and $18.3 \%$ reporting being part of an Identification of Poor (IDPoor) household (22). IDPoor is a mechanism developed by Cambodia Ministry of planning to identify poor and vulnerable households for development programs in Cambodia. 
In Vietnam, a majority of the sampled forest goers were married (84.8\%), male (95.2\%), and between the age of $25-34$ years $(52.5 \%)$. In Vietnam, forest goers under 35 years constituted over $70 \%$ of all forest goers sampled, while the age distribution in the Cambodian forest goers was more evenly spread across the age groups. A majority of forest goers in Vietnam made their living through agriculture, and similar to Cambodia, almost all (99.7\%) made less than USD 500 per month.

Forest goers in Vietnam were long-standing residents of their villages, with a majority (96.6\%) having lived there for more than 10 years. In Cambodia, there was variation in length of stay, with $25.5 \%$ of residents living in their village less than 10 years and $29.2 \%$ living in there for 30 years or more. Table 2 shows the weighted demographic characteristics of forest goers in Cambodia and Vietnam. 
Table 2

Weighted Demographic Characteristics of Forest Goers

\section{Cambodia}

Weighted Population
Proportion

(Bootstrapped 95\%

$\mathrm{Cl})$

Vietnam

Unweighted Sample

$\mathbf{N}$
Weighted Population

Proportion

(Bootstrapped 95\%

Cl)
Unweighted

Sample

N

\section{Gender}

Male

$85.5(80.9-89.1)$

14.5(10.9-19.1)

591

84

133

127

115

$17.1(13.5-20.8)$

$17.4(13.8-21.0)$

$26.7(22.2-31.5)$

120

180

100

198

$24.8(20.8-29.4)$

Attended school,

but never

completed

Primary schoo

$47.8(42.5-52.7)$

300

70

Lower Secondary $11.7(8.6-15.0)$

school

Upper

$1.3(0.4-2.4)$

7
$95.2(91.5-98.0)$

$4.8(2.0-8.5)$

$21.2(16.4-25.9)$

$23.0(18.5-27.5)$

$29.5(24.3-34.6)$

13.8 (8.7-18.9)

$12.6(9.3-15.8)$

82

633

15

120

162

196

88

38

$6.0(3.8-8.4)$

$35.5(28.5-42.7)$ 148

Secondary or

Higher

No response

-

-

$21.1(13.8-302$,

105

Income

$<\$ 500$

95.4 (93.6-97.1)

637

99.7 (99.1-99.9)

640

$>\$ 500$

$3.9(2.4-5.5)$

33

$0.3(.05-.9)$

8

Don't know

$0.8(0.1-1.7)$

5 


\section{Cambodia}

\section{Vietnam}

ID Poor[1]

$\begin{array}{lll}\text { No } & 81.7(77.5-85.9) & 558 \\ \text { Yes } & 18.3(14.1-22.5) & 117\end{array}$

\section{Occupation}

$\begin{array}{lllll}\text { Agriculture } & 16.3(13.0-20.0) & 125 & 58.3(51.1-64.3) & 389 \\ \text { Forest related } & 77.9(73.6-81.8) & 507 & 26.9(21.6-32.9) & 165 \\ \text { Others } & 5.7(3.6-8.6) & 43 & 15.0(11.1-19.7) & 94\end{array}$

\section{Marital Status}

$\begin{array}{lllll}\text { Currently married } & 84.3(80.5-87.7) & 568 & 84.8(79.8-89.2) & 571 \\ \begin{array}{l}\text { Single or } \\ \text { formerly married }\end{array} & 15.7(12.3-19.5) & 107 & 15.2(10.8-20.2) & 77\end{array}$

\section{Time at place of residence}

\begin{tabular}{|lllll|}
\hline 10 yrs or less & $25.3(20.8-30.1)$ & 156 & $3.4(1.8-5.8)$ & 39 \\
\hline $11-20$ yrs & $26.9(22.6-31.6)$ & 184 & $8.6(5.7-11.7)$ & 79 \\
\hline $21-30$ yrs & $27.9(23.4-32.5)$ & 199 & $44.5(38.7-50.5)$ & 267 \\
\hline More than 30 yrs & $29.9(15.6-24.5)$ & 135 & $43.5(37.8-49.2)$ & 263 \\
\hline
\end{tabular}

[1] IDPoor is a mechanism developed by Cambodia Ministry of planning to identify poor and vulnerable households for development programs in Cambodia

\subsection{Forest going and activities in the forest}

The primary reason for going to the forest was cutting wood (85\%) for Cambodian forest goers while only $17.9 \%$ went for wood in Vietnam. Bamboo (15.4\%) and Charcoal $(14.7 \%)$ were other reasons for going to forest in Cambodia. In Vietnam, plantation work was the main reason for going to forest, $28 \%$ worked in cashew plantation while $27.7 \%$ went for wheat plantation and $19.4 \%$ went for Rubber plantation. In Cambodia, $78.4 \%$ went to the forest for one reason only and $18 \%$ went for two or more reasons. Forest goers in Vietnam reported spending more nights in the forest in the last 30 days compared to forest goers in Cambodia. Almost two-thirds (71.1\%) of forest goers in Cambodia and more than half $(54.2 \%)$ in Vietnam reported spending seven nights or fewer in the forest in the last 30 days. Forest goers in Vietnam reported spending a longer time in the forest, with $23.6 \%$ in Vietnam spending 8-14 nights and $22.3 \%$ spending 15 nights or more in the forest in the last 30 days. Comparatively only $8.5 \%$ of forest goers in Cambodia spent 15 nights or in the forest. The interval between forest visits was longer in Cambodia. Almost one-fifth (19.8\%) of the forest goers in Cambodia had an interval of 15 or more days since the 
most recent forest visit compared to $14 \%$ in Vietnam. A majority of forest goers in Cambodia and Vietnam reported having been to the forest in the last 7 days ( $69.8 \%$ and $76.6 \%$ respectively). 
Table 3

Weighted Forest Going and Activities in Forest

Cambodia

Weighted

Population

Proportion

(Bootstrapped 95\%

$\mathrm{Cl})$
Vietnam

Unweighted Weighted

Sample N
Population

Proportion

(Bootstrapped 95\%

$\mathrm{Cl})$
Unweighted

Sample N

\section{Reasons for going to the forest*}

Wood

85.1 (80.9-88.8)

675

$17.9(14.3-22.1)$

648

Charcoal

$14.7(10.3-20.1)$

675

Bamboo

$15.4(10.7-21.0)$

675

Fishing

Rubber plantation

-

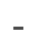

$-$

Cashew plantation

Wheat plantation

Others

\section{Number of reasons for} going to forest

One

Two

Three or more

\section{Nights spent in forest} in last $\mathbf{3 0}$ days

Short ( $<=7$ days)

$71.1(66.8-74.8)$

434

161

$20.5(16.9-24.3)$

$8.5(6.4-10.9)$

80

Long (15+ days)

\section{Last time in forest}

7 days or less

8-14 days
$69.8(65.0-74.7)$

$10.4(7.6-13.1)$
524

123

28
$49.7(43.8-55.6)$

292

$41.7(35.9-47.4) \quad 250$

$8.6(6.0-11.2)$

$35.5(28.7-42.8) \quad 648$




\begin{tabular}{|c|c|c|c|c|}
\hline & Cambodia & & Vietnam & \\
\hline $15+$ days & $19.8(15.9-24.0)$ & 133 & $14.0(10.4-17.6)$ & 121 \\
\hline
\end{tabular}

\subsection{Health care seeking behavior}

All respondents from Cambodia and $65.8 \%$ of respondents from Vietnam reported having febrile illness in the last 30 days. More than half (52.2\%) of respondents in Cambodia reported suspecting that their febrile illness was malaria, $13.4 \%$ had a cold, $10.1 \%$ had Krunkdov/kdovkhlounr (general fever) and 9.5\% had typhoid. In Vietnam, $41.6 \%$ of the cases were flu, followed by malaria (30.1\%), cold (15.5\%) and other febrile illnesses $(11.9 \%)$. Less than half $(42.9 \%)$ of the forest goers in Vietnam had a blood test following the febrile illnesses with almost all who did (94.5\%) visiting a public health or community health facility for the blood test. In Cambodia, $66.5 \%$ of the forest goers went for a blood test with $36.7 \%$ seeking testing from community health workers, followed by private health facility (33.6\%) and public health facility mostly health centers $(28.0 \%)$. In Vietnam, $73.1 \%$ of those who received a blood test were tested positive for malaria, while $62.5 \%$ tested positive for malaria in Cambodia.

The majority of the forest goers in both countries sought treatment for illness. Bivariable analysis showed that seeking treatment from any source was significantly associated with age $\left(X^{2}=9.7, P<.001\right)$ and gender $\left(\chi^{2}=27.3, P<001\right)$ for Vietnam while results were not significant for Cambodia. Three-fourths $(75 \%)$ of the forest goers in Cambodia sought treatment outside of their home for febrile illness, $17.4 \%$ did not seek any treatment and $7.6 \%$ were treated in their home. In Vietnam, $65.3 \%$ of those with febrile illness sought treatment outside of their home and $7.3 \%$ sought treatment at their home. However, more than a quarter $(27.4 \%)$ of those with febrile illness did not seek any treatment.

In Cambodia, $39 \%$ of those seeking care for febrile illness first sought treatment from the private sector, followed by community health workers (32.4\%) and public health facilities $(24.1 \%)$. For Vietnam, $62.3 \%$ sought care from community facilities and $29.3 \%$ from the private sector, while only $6.9 \%$ went to a public facility. The comparison between place for blood test and first place of treatment suggests that some forest goers in Vietnam opted to go to the private sector after getting blood test in the public sector. The first place of treatment was significantly associated with age $\left(X^{2}=2.4, P<.05\right)$ and perceived malaria infection $\left(\chi^{2}=9.0, P<.001\right)$ for Cambodia. Associations were not significant for Vietnam. A similar shift between community health workers and private health facilities was observed in Cambodia. Amongst Cambodian forest goers who sought care, $33.1 \%$ did so within 24 hours, $38.4 \%$ sought care within $24-48$ hours and $28.5 \%$ waited for three or more days before seeking care for the febrile illness. In Vietnam, more than half $(51.6 \%)$ of those who sought care for febrile illness did so within 24 hours, $13.4 \%$ sought care in 24-48 hours and 35\% sought care after 48 hours. Time to seeking treatment was associated with age $\left(\chi^{2}=3.4, P<.01\right)$ in Cambodia. Results were not significant for gender or education. 
$69.4 \%$ of the forest goers in Cambodia sought treatment for their illness from one place while $30.6 \%$ went to two or more places. In Vietnam, a majority (58.2\%) of forest goers visited more than one place. Table 4 shows key variables in health seeking behavior of forest goers in Cambodia and Vietnam. 
Table 4

Health Care Seeking Behavior of Forest Goers

Cambodia

Weighted

Population

Proportion

(Bootstrapped

95\% Cl)
Vietnam

Unweighted Weighted

Sample N Population

Proportion

(Bootstrapped

$95 \% \mathrm{Cl}$ )

Fever in last 30 days

\begin{tabular}{|c|c|c|c|c|}
\hline Yes & 100 & 675 & $65.8(60.0-71.3)$ & 427 \\
\hline No & - & - & $34.2(28.7-40.0)$ & 221 \\
\hline $\begin{array}{l}\text { Kind of febrile illness } \\
\text { suspected by forest goers }\end{array}$ & & & $(n=427)$ & \\
\hline Malaria & $52.2(47.3-57.2)$ & 334 & $30.1(23.1-38.1)$ & 124 \\
\hline Dengue & $4.8(2.9-7.0)$ & 29 & $1.0(0.2-2.2)$ & 6 \\
\hline Typhoid & $9.5(7.0-12.3)$ & 70 & - & \\
\hline Cold & $13.4(10.0-17.3)$ & 97 & $15.5(10.8-21.0)$ & 115 \\
\hline Flu & $2.8(1.4-4.2)$ & 17 & $41.6(33.4-50.1)$ & 155 \\
\hline $\begin{array}{l}\text { Krunkdov/kdovkhlounr } \\
\text { (general fever) }\end{array}$ & $10.1(7.4-13.2)$ & 79 & - & \\
\hline Other/Don't know & $7.3(5.0-9.8)$ & 51 & $11.9(4.6-19.6)$ & 27 \\
\hline Blood testing & & & $(n=427)$ & \\
\hline Yes & $66.5(61.8-71.7)$ & 459 & $42.9(34.8-51.2)$ & 199 \\
\hline No & $33.5(28.3-38.2)$ & 216 & $50.6(42.7-58.8)$ & 211 \\
\hline Don't know & - & - & $6.5(3.0-10.7)$ & 17 \\
\hline Place of blood testing & $(n=459)$ & & $(n=199)$ & \\
\hline Public health facility & $28.0(20.4-36.7)$ & 105 & $94.5(89.7-98.2)$ & 175 \\
\hline $\begin{array}{l}\text { Private health facility } \\
\text { (includes pharmacy/ } \\
\text { chemist / drug shop) }\end{array}$ & $33.8(26.5-41.2)$ & 181 & $\mathrm{n} / \mathrm{a}$ & $\mathrm{n} / \mathrm{a}$ \\
\hline Community health worker & $36.7(27.9-45.8)$ & 162 & - & - \\
\hline Others & $1.5(0.5-2.6)$ & 11 & $5.5(1.8-10.3)$ & 24 \\
\hline Result of blood test & $(n=459)$ & & $(n=199)$ & \\
\hline
\end{tabular}




\begin{tabular}{|c|c|c|c|c|}
\hline & Cambodia & & Vietnam & \\
\hline Positive for malaria & $62.5(55.4-69.7)$ & 253 & $73.1(54.7-90.3)$ & 116 \\
\hline $\begin{array}{l}\text { Negative/inconclusive for } \\
\text { malaria }\end{array}$ & $21.2(15.7-27.0)$ & 114 & $20.3(3.2-39.5)$ & 12 \\
\hline Non-malaria diagnosis & $15.5(10.2-21.4)$ & 85 & $6.6(2.1-12.6)$ & 71 \\
\hline No response & $0.8(0.1-2.4)$ & 7 & - & - \\
\hline $\begin{array}{l}\text { Sought treatment for } \\
\text { illness from any source }\end{array}$ & & & $(n=427)$ & \\
\hline Yes & $82.6(78.9-85.9)$ & 526 & $67.8(59.4-75.4)$ & 303 \\
\hline No & $17.4(14.1-21.1)$ & 149 & $27.6(20.6-35.4)$ & 111 \\
\hline No response & - & - & $4.6(1.6-8.2)$ & 13 \\
\hline $\begin{array}{l}\text { Sought treatment for } \\
\text { illness outside of home }\end{array}$ & & & $(n=427)$ & \\
\hline Yes & $75.0(70.9-79.2)$ & 481 & $65.3(57.0-72.9)$ & 279 \\
\hline No & $7.6(5.2-10.3)$ & 45 & $7.3(4.0-11.3)$ & 37 \\
\hline $\begin{array}{l}\text { Did not seek treatment for } \\
\text { illness }\end{array}$ & $17.4(14.1-20.9)$ & 149 & $27.4(20.7-35.2)$ & 111 \\
\hline $\begin{array}{l}\text { First place sought } \\
\text { treatment from }\end{array}$ & $(n=526)$ & & $(n=303)$ & \\
\hline Public health facility & $24.1(17.9-30.6)$ & 111 & $6.9(3.7-10.5)$ & 21 \\
\hline $\begin{array}{l}\text { Private health facility } \\
\text { (includes pharmacy/ } \\
\text { chemist / drug shop) }\end{array}$ & $39.0(32.2-45.6)$ & 252 & $29.3(18.9-40.2)$ & 81 \\
\hline Community health Worker & $32.4(25.9-39.4)$ & 138 & - & - \\
\hline Community health Facility & - & - & $62.3(51.4-72.5)$ & 187 \\
\hline Other & $4.6(2.6-6.9)$ & 25 & $1.5(0.3-4.1)$ & 14 \\
\hline Time to seek treatment & $(n=526)$ & & $(n=303)$ & \\
\hline$\leq 24$ hours $(0-1$ days $)$ & $33.1(27.2-39.3)$ & 174 & $51.6(36.0-65.8)$ & 81 \\
\hline 48 hours (2 days) & $38.4(32.7-44.2)$ & 205 & $13.4(8.0-20.2)$ & 75 \\
\hline$>48$ hours ( $\geq 3$ days) & $28.5(22.9-34.4)$ & 146 & $35.0(23.4-48.4)$ & 147 \\
\hline $\begin{array}{l}\text { Number of places sought } \\
\text { treatment from }\end{array}$ & $(n=525)$ & & $(n=303)$ & \\
\hline
\end{tabular}




\begin{tabular}{|c|c|c|c|c|}
\hline & Cambodia & & Vietnam & \\
\hline One place & $69.4(63.6-74.6)$ & 380 & $41.8(33.0-50.2)$ & 172 \\
\hline More than one & $30.6(25.4-36.3)$ & 145 & $58.2(49.8-67.0)$ & 260 \\
\hline Second place of treatment & $(n=525)$ & & & \\
\hline Public health facility & $6.0(3.7-9.0)$ & 30 & $\mathrm{n} / \mathrm{a}$ & $\mathrm{n} / \mathrm{a}$ \\
\hline $\begin{array}{l}\text { Private health facility } \\
\text { (includes pharmacy, } \\
\text { chemist, and drug shop) }\end{array}$ & $22.0(17.1-27.5)$ & 104 & n.a & n.a \\
\hline Others & $2.5(0.9-4.6)$ & 11 & $\mathrm{n} / \mathrm{a}$ & $\mathrm{n} / \mathrm{a}$ \\
\hline $\begin{array}{l}\text { Sought treatment at one } \\
\text { place only }\end{array}$ & $69.4(63.1-74.5)$ & 380 & $\mathrm{n} / \mathrm{a}$ & $\mathrm{n} / \mathrm{a}$ \\
\hline
\end{tabular}

\subsection{Preferred place of treatment}

Private health facilities (41.2\%) were the most preferred place of treatment for febrile illness, followed by community health workers (31.4\%) and public health facilities (25.3\%) among forest goers in Cambodia (Table 5). In Vietnam, 44.5\% preferred community health facilities, followed by private health facilities (39.3\%) and public health facilities (10.8\%). Table 6 shows the breakdown of forest goers' preferred place of treatment in Cambodia and Vietnam. In both countries preferred place of treatment was significantly associated with age of the forest goers (Cambodia: $\chi^{2}=3.3, P<.05$; Vietnam: $\chi^{2}=12.5, P<.001$ ). The results were not significant for education, income and gender. 
Table 5

Preferred Place of Treatment

Cambodia

Weighted

Population

Proportion

(Bootstrapped

95\% Cl)
Vietnam

Unweighted

Sample N
Weighted

Population

Proportion

(Bootstrapped

95\% Cl)

\section{Preferred place of treatment}

\begin{tabular}{lllll} 
Public health facility & $25.3(20.3-30.7)$ & 155 & $10.8(7.9-13.9)$ & 97 \\
\hline Private health facility & $41.2(35.7-46.7)$ & 337 & $39.3(32.6-46.2)$ & 208
\end{tabular}

(includes pharmacy, chemist, and drug shop)

Community health Worke

$31.4(25.6-37.6)$

168

Community health facility

Other

$2.1(0.8-3.7)$

15

$44.5(38.2-50.9)$

308

$5.4(3.3-8.1)$

35

Unweighted

Sample N 
Table 6

Reasons for Preference

Cambodia

Weighted

Population

Proportion

(Bootstrapped

$95 \% \mathrm{Cl}$ )
Vietnam

Unweighted

Sample N
Weighted

Population

Proportion

(Bootstrapped

95\% Cl)

\section{Top ranked reasons for}

place of preference

\begin{tabular}{lllll} 
Proximity & $37.7(32.7-43.1)$ & 239 & $87.8(84.2-91.0)$ & 549 \\
\hline Cost & $14.6(11.3-18.0)$ & 97 & $4.7(3.0-6.8)$ & 38 \\
\hline Previous experience & $7.8(5.3-10.4)$ & 56 & $3.4(1.8-5.2)$ & 32 \\
\hline Recommended provider & - & - & $1.3(0.5-2.3)$ & 18 \\
\hline Quality of Service & $16.3(12.6-20.4)$ & 102 & $1.9(0.4-4.0)$ & 6 \\
\hline Friendliness of service & $5.4(3.4-7.6)$ & 38 & $0.8(0.1-2.4)$ & 5 \\
\hline Trust in provider & $15.2(11.9-18.8)$ & 121 & - & - \\
\hline Others & $3.2(1.8-4.8)$ & 22 & - & -
\end{tabular}

\section{Second ranked reasons for} place of preference

Proximity
Cost

$10.1(7.2-13.3)$

$36.5(31.7-41.2) \quad 208$

$68.0(62.6-73.4) \quad 417$

Previous experience

$6.0(3.8-8.7)$

44

$16.3(12.2-20.6)$

107

Recommended provider

Quality of Service

$15.8(12.4-19.7) \quad 96$

$4.7(2.9-7.0)$

32

Friendliness of service

$10.0(7.0-13.0)$

56

$6.3(4.4-8.5)$

72

Availability of service

Trust in provider

16.8 (13.0-21.1)

112

Others

$4.7(2.7-7.0)$

30

Third ranked reasons for place of preference

Proximity

$11.1(7.9-14.7) \quad 64$

Cost

$18.1(14.2-22.3) \quad 95$




\begin{tabular}{|lllll|}
\hline \multicolumn{2}{l}{ Cambodia } & \multicolumn{3}{l|}{ Vietnam } \\
\hline Previous experience & $5.4(3.1-8.4)$ & 34 & $16.5(12.5-20.8)$ & 163 \\
\hline Recommended provider & - & - & $2.5(1.4-3.8)$ & 28 \\
\hline Quality of Service & $11.6(8.2-15.2)$ & 68 & $5.6(3.5-7.9)$ & 52 \\
\hline Friendliness of service & $10.3(7.0-13.9)$ & 64 & $13.4(10.3-16.8)$ & 102 \\
\hline Availability of service & - & - & $45.8(39.4-52.2)$ & 168 \\
\hline Trust in provider & $38.8(32.8-44.9)$ & 194 & $16.1(12.4-20.0)$ & 131 \\
\hline Others & $4.7(2.2-8.3)$ & 27 & 0 & 4 \\
\hline
\end{tabular}

In Cambodia, cost $(O R=5.19, P<.001)$, quality of service $(O R=2.28, p<0.001)$, friendliness of service $(O R=2.48, p<0.001)$ and availability of service $(O R=6.42, p<0.001)$ were positively associated with the preference of public health facility while trust in provider $(O R=0.38, p<0.001)$ was negatively associated with the preference (Table 7).

Trust in provider $(O R=1.58, p<0.05)$ and other reasons $(O R=4.01, p<0.05)$ were positively associated with preference of private facility. Cost $(O R=0.25, p<0.001)$, proximity $(O R=0.33, p<0.001)$, recommended provider $(O R=0.11, p<0.01)$ and availability of service were negatively associated with preference of private facility in Cambodia.

Proximity $(O R=4.81, p<0.01)$, recommended provider $(O R=9.84, p<0.001)$ and trust in provider $(O R=$ $1.68, p<0.05$ ) were associated positively with the preference of community health workers in Cambodia. Quality of services and friendliness of service were negatively associated with the preference of community health workers.

In Vietnam, cost $(O R=5.36, p<0.01)$, and recommended provider $(O R=3.94, p<0.01)$ were positively associated with the preference of public health facility while only availability of service $(O R=3.19, p<$ 0.001) was positively associated with the private health facility. Quality of the service was not included in the public health facility analysis due to low number of mentions as reasons for preference. Proximity, cost, quality of service and friendliness of service were negatively associated with the private providers. Despite being the preferred place of almost half of the forest goers, none of the factors were positively associated with the choice of community health facility. There could be other factors associated with choice which is not captured by this study. 
Table 7

Weighted Odds Ratios for the Reasons for Choice of Facility

\begin{tabular}{|lll|}
\hline Cambodia & Odds Ratio & p-value \\
\hline Public Facility & & \\
\hline Cost & 5.19 & $<0.001$ \\
\hline Quality of service & 2.28 & $<0.001$ \\
\hline Friendliness of service & 2.48 & $<0.001$ \\
\hline Availability of service & 6.42 & $<0.001$ \\
\hline Trust in provider & 0.38 & $<0.001$ \\
\hline Private Facility & & \\
\hline Proximity & 0.33 & $<0.001$ \\
\hline Cost & 0.25 & $<0.001$ \\
\hline Recommended provider & 0.11 & $<0.001$ \\
\hline Availability of service & 0.37 & 0.004 \\
\hline Trust in provider & 1.58 & 0.012 \\
\hline Others & 4.01 & 0.012 \\
\hline Community Health Workers & & 0.001 \\
\hline Proximity & 4.81 & $<0.001$ \\
\hline Recommended provider & 9.84 & 0.001 \\
\hline Quality of service & 0.35 & $<0.001$ \\
\hline Friendliness of service & 0.39 & 0.002 \\
\hline Trust in provider & 1.68 & 0.027 \\
\hline Vietnam & 0.16 -value \\
\hline Public Facility & 3.94 & 0.009 \\
\hline Cost & 0.26 & 0.021 \\
\hline Recommended provider & & \\
\hline Availability of service & & \\
\hline Private Facility & & \\
\hline Proximity & & \\
\hline
\end{tabular}




\begin{tabular}{|lll|}
\hline Cambodia & Odds Ratio & p-value \\
\hline Cost & 0.57 & 0.011 \\
\hline Quality of service & 0.15 & $<0.001$ \\
\hline Friendliness of service & 0.17 & $<0.001$ \\
\hline Availability of service & 3.19 & $<0.001$ \\
\hline Community Health Facility & & \\
\hline Cost & 0.11 & $<0.001$ \\
\hline Previous experience & 0.09 & 0.001 \\
\hline Recommended provider & 0.08 & $<0.001$ \\
\hline Quality of service & 0.01 & $<0.001$ \\
\hline Friendliness of service & 0.24 & 0.006 \\
\hline Availability of service & 0.02 & $<0.001$ \\
\hline Trust in provider & 0.06 & 0.012 \\
\hline
\end{tabular}

\section{Discussion}

In both countries most of the forest goers were married men. Between $50 \%$ and $60 \%$ of forest goers were under 35 in Vietnam and Cambodia. Forest goers in Vietnam spent more nights in the forest in the last 30 days compared to forest goers in Cambodia. This was consistent with studies that have explored the behaviors of forest goers in Vietnam and mobile migrant populations (MMPs) in western Cambodia, finding that forest goers spend extended periods in the forest, sleep in temporary structures and do not routinely use long-lasting insecticidal nets (LLINs) resulting in increased risk of malaria (23).

\section{Care seeking behaviors amongst forest goers}

This study is consistent with others that show that early diagnosis and treatment of malaria remains an obstacle to malaria control and elimination activities. In Cambodia and Vietnam the national guidance is for all suspected malaria patients to receive a parasitological test (24). However, this study demonstrates that among those most at risk of malaria - forest goers in Cambodia - $25 \%$ either did not seek treatment at all or were treated at home ( $17.4 \%$ and $7.6 \%$ respectively). This study also demonstrates that there are gaps in timeliness of care seeking amongst forest goers. In Vietnam only $33 \%$ of forest goers sought care within the 24 hour WHO recommendation with $38.4 \%$ seeking care within $24-48$ hours and $28.5 \%$ not seeking care for more than three days. Amongst Cambodian forest goers who sought care, only about one-third did so within 24 hours. These findings are somewhat clarified by qualitative research into health seeking journeys in the GMS context where economic pressures drive forest activities. Furthermore, efforts to protect work time and corresponding income have a strong impact on decisions to abandon 
economic activities in the interest of seeking medical attention. Studies have found that an individual's health seeking behaviors are not a static construct but rather influenced by the individual's classification of the illness (25). Classification of an illness into 'small' or 'big' impacts their health seeking journey for that episode (15). Ultimately, the perceived severity of an illness has an impact on the decisions regarding if and when to seek care. Ironically, the combined impact of significant reductions in malaria incidence and death combined with the increased access to health at the village level in both Vietnam and Cambodia has lessened the perceived severity of the disease potentially compromising the individual's perceived need to seek early care (25). Furthermore, forest goers often begin self-treatment when they are in the forest or before they go into the forest $(5,26)$.

\section{Preferred Source of care}

All respondents in Cambodia and more than $60 \%$ in Vietnam reported febrile illness in last 30 days as this was part of the inclusion criteria. Of those reporting febrile illness, one in two in Cambodia and one-third in Vietnam mentioned they had malaria. The majority of those seeking treatment for febrile illness in Cambodia sought private health care. This finding is consistent with a prior study from western Cambodia where more than half of study participant sought care from private sector (23). Similarly, in a study conducted in the Bago region of Myanmar, migrant workers preferred to seek care from the private or informal healthcare sector because of convenience, trust and availability of low-cost antimalarial medication (27). In a study previously conducted in Kampot, Cambodia, majority of forest goers sought care in the private sector and cited factors influencing care-seeking behavior that included proximity, reputation of the provider, trust, and perceived severity (15).

A review of qualitative literature from the Mekong region showed that despite free diagnosis and treatment services in the public sector, forest goers often sought services in the private sector due to service quality and accessibility (10). This is in contrast to the findings in this study where a higher proportion of respondents in Vietnam sought care from community health facilities and only one-third sought care from the private sector (5). This may be explained by the fact that Vietnam has a wellestablished public healthcare network that extends to the commune level and includes of a strong community-level health service. Anthropological studies in Vietnam also report a strong confidence by the community in the public health system at the community level (6). However, concerns around gaps in the coverage of the public health system for migrants have been observed in situations when national identification is required to access care, making private sector services a necessary option for care (5).

Community-based interventions are often a first source of treatment for malaria in remote areas where access to formal health services is limited (28). In Cambodia, however, VMWs specialize only in malaria prevention and case management, which likely explains why they were not usually the first point of care amongst the forest goers in this study (15). Furthermore, community volunteers often juggle service provision with paid employment and can be perceived as an unreliable service option due to unavailability in remote areas (10). Just over $7 \%$ in both countries sought treatment at home in this study, consistent with previous studies that have identified the use of an array of treatment options, including 
traditional methods and over-the-counter drugs from pharmacies and other vendors for self-treatment (10).

The comparison between place for blood test and first place of treatment suggests that some forest goers opt to go to the private sector after getting a blood test in the public sector; similar transitions between provider types were observed in Cambodia where patients shifted between using community health workers and the private sector. This use of multiple types of providers appears to be more prominent in Vietnam than in Cambodia, where a majority of the forest goers sought treatment from one place; in Vietnam, the majority visited more than one place. These findings suggest that provider preference is not static and is influenced along the journey of the patient's experience.

This study shows that cost, quality of service, friendliness of service and availability of service are key factors for choosing a public health facility in Cambodia. In a study conducted in rural Cambodia, villagers provided different reasons for trusting public and private providers. Public providers were trusted because of their abilities and the presence of an effective referral system. On the other hand, private providers were trusted because they were friendly, thorough and easy to contact (29). However, in this study, trust in provider was negatively associated with the choice of public provider but positively associated with the choice of private facility. In Vietnam, cost, recommended provider and quality of service were positively associated with the choice of public health facility while only availability of service was positively associated with the private health facility. Despite being preferred place, almost half of the forest goers, none of the forest goers positively associated with the preference for community health facility with the factors measured in this study.

\section{Conclusion}

Forest going remains a major risk factor for malaria in Cambodia and Vietnam; however, economic pressures compel people to undertake this activity. With the rapid decline of malaria in both countries, malaria has become more concentrated geographically and amongst the most at risk populations. Studies using RDS are a powerful means of gathering insights into the behaviors of forest-goers who are otherwise difficult to access. The findings from this study around provider preference and delays in treatment seeking behaviors can be utilized to strengthen the design and targeting of malaria interventions, as well as social behavior change strategies in order to accelerate malaria elimination in Cambodia and Vietnam.

\section{Declarations}

\section{Ethics Approval and Consent to Participate}

This study was approved by the PSI Research and Ethics Board (REB), as well as local boards in Cambodia the National Ethics Committee for Health Research and in Vietnam the Hanoi School of Public Health (Vietnam). 


\section{Consent for Publication}

Not applicable

\section{Availability of Data and Materials}

The datasets used and analyzed during the current study are available from the corresponding author on reasonable request.

\section{Competing Interests}

The authors declare that they have no competing interests.

\section{Funding}

This study was funded by the Bill \& Melinda Gates Foundation.

\section{Authors' Contributions}

MP contributed to study design, conducted the analysis, and contributed to the background, methods, results, discussion and conclusion sections. KT was responsible for oversight of the study and contributed to the background, discussion and conclusions sections. SP conducted RDS analysis analysis for Cambodia and supervised the field data collection. HN conducted RDS analysis for Vietnam and supervised the field data collection. SS contributed to the data analysis and literature review. JW contributed to study design, provided guidance on the analysis and structure of the paper, and contributed to the background, methods, results, discussion and conclusion sections. All authors read and approved the final manuscript.

\section{Acknowledgements}

The study team is grateful to the Bill \& Melinda Gates Foundation for funding the study. We also thank Lorina McAdam, M. James Eliades, and Susannah Gibbs for their insights and support. The team also thanks the field teams in Cambodia and Vietnam, for their tireless dedication to study implementation and use of findings for programmatic improvement.

\section{References}

1. WHO WHO. World Malaria. Report 20192019 [Available from: https://www.who.int/publications/i/item/9789241565721.

2. WHO WHO. Countries of the Greater Mekong making inroads in the race towards elimination. 2017 [cited 2021 2021]. Available from: https://www.who.int/malaria/publications/atoz/greater-mekongbulletin-6/en/. 
3. Canavati SE. Kelly GC, Quintero CE. Vo TH, Tran LK. Ohrt C, et al. Risk factor assessment for clinical malaria among forest-goers in a pre-elimination setting in Phu Yen Province, Vietnam. Malar J. 2019;18(1):435.

4. Van Bortel W. Trung HD, Hoi le X, Van Ham N. Van Chut N, Luu ND, et al. Malaria transmission and vector behaviour in a forested malaria focus in central Vietnam and the implications for vector control. Malar J. 2010;9:373..

5. Chen I. Thanh HNT, Lover A. Thao PT, Luu TV. Thang HN, et al. Malaria risk factors and care-seeking behaviour within the private sector among high-risk populations in Vietnam: a qualitative study. Malar J. 2017;16(1):414.

6. WHO WHO. National malaria programme review - Viet Nam Manila, Philippines2018 [.

7. Gryseels C. Peeters Grietens K, Dierickx S. Xuan XN, Uk S. Bannister-Tyrrell M, et al. High Mobility and Low Use of Malaria Preventive Measures Among the Jarai Male Youth Along the Cambodia-Vietnam Border. Am J Trop Med Hyg. 2015;93(4):810-8.

8. Guyant P. Canavati SE, Chea N. Ly P, Whittaker MA. Roca-Feltrer A, et al. Malaria and the mobile and migrant population in Cambodia: a population movement framework to inform strategies for malaria control and elimination. Malar J. 2015;14:252.

9. Dysoley L. Kaneko A, Eto H. Mita T, Socheat D. Borkman A, et al. Changing patterns of forest malaria among the mobile adult male population in Chumkiri District, Cambodia. Acta Trop. 2008;106(3):207-12.

10. Nofal SD. Peto TJ, Adhikari B. Tripura R, Callery J. Bui TM, et al. How can interventions that target forest-goers be tailored to accelerate malaria elimination in the Greater Mekong Subregion? A systematic review of the qualitative literature. Malar J. 2019;18(1):32.

11. Wangroongsarb P. Sudathip P, Satimai W. Characteristics and malaria prevalence of migrant populations in malaria-endemic areas along the Thai-Cambodian border. Southeast Asian $\mathrm{J}$ Trop Med Public Health. 2012;43(2):261-9.

12. National Institute of Malariology PaEN. National strategy for malaria control and elimination in the period 2011-2020 and orientation to 2030. Vietnam: Vietnam National Institute of Malariology, Parasitology, and Entomology:; 2011.

13. WHO WHO. Global technical strategy for malaria 2016-2030. World Health Organization.; 2015.

14. Yeung S. Van Damme W, Socheat D. White NJ, Mills A. Access to artemisinin combination therapy for malaria in remote areas of Cambodia. Malar J. 2008;7:96.

15. Liverani M. Nguon C, Sok R. Kim D, Nou P. Nguon S, et al. Improving access to health care amongst vulnerable populations: a qualitative study of village malaria workers in Kampot, Cambodia. BMC Health Serv Res. 2017;17(1):335.

16. Hewitt S. A review of Cambodia's village malaria worker project. Phnom Penh: World Health Organization; 2012.

17. Canavati SE. Quintero CE, Lawford HL. Yok S, Lek D. Richards JS, et al. High mobility, low access thwarts interventions among seasonal workers in the Greater Mekong Sub-region: Iessons from the 
malaria containment project. Malar J. 2016;15(1):434.

18. Johnston LG. Hakim AJ, Dittrich S. Burnett J, Kim E. White RG. A Systematic Review of Published Respondent-Driven Sampling Surveys Collecting Behavioral and Biologic Data. AIDS Behav. 2016;20(8):1754-76.

19. Heckathorn DD. Respondent-Driven Sampling: A New Approach to the Study of Hidden Populations.. Social Problems 1997;44.

20. Heckathorn DD. Respondent-Driven Sampling II. Deriving Valid Population Estimates from ChainReferral Samples of Hidden Populations. Soc Probl. 2002;49,:11-34.

21. Magnani R. Sabin K, Saidel T. Heckathorn D. Review of sampling hard-to-reach and hidden populations for HIV surveillance. AIDS. 2005;19 Suppl 2:67-72.

22. Cambodia RGo. ID Poor Process 2021 [Available from: https://www.idpoor.gov.kh/about/process.

23. Ly P. Thwing J, McGinn C. Quintero CE, Top-Samphor N. Habib N, et al. The use of respondent-driven sampling to assess malaria knowledge, treatment-seeking behaviours and preventive practices among mobile and migrant populations in a setting of artemisinin resistance in Western Cambodia. Malar J. 2017;16(1):378.

24. Health KoCMo. Cambodia Malaria Elimination Action Framework 2016-2020. 2016.

25. Taffon P. Keep the Force to Keep the Order Facing malaria in the Cambodian forest An ethnographic study.. 2016.

26. Bannister-Tyrrell M. Gryseels C, Sokha S. Dara L, Sereiboth N. James N, et al. Forest Goers and Multidrug-Resistant Malaria in Cambodia: An Ethnographic Study. Am J Trop Med Hyg. 2019;100(5):1170-8.

27. Win AYN. Maung TM, Wai KT. Oo T, Thi A. Tipmontree R, et al. Understanding malaria treatmentseeking preferences within the public sector amongst mobile/migrant workers in a malaria elimination scenario: a mixed-methods study. Malar J. 2017;16(1):462.

28. Wangroongsarb P. Satimai W, Khamsiriwatchara A. Thwing J, Eliades JM. Kaewkungwal J, et al. Respondent-driven sampling on the Thailand-Cambodia border. II. Knowledge, perception, practice and treatment-seeking behaviour of migrants in malaria endemic zones. Malar J. 2011;10:117.

29. Ozawa S. Walker DG. Comparison of trust in public vs private health care providers in rural Cambodia. Health Policy Plan. 2011;26 Suppl 1:i20-9.

\section{Figures}




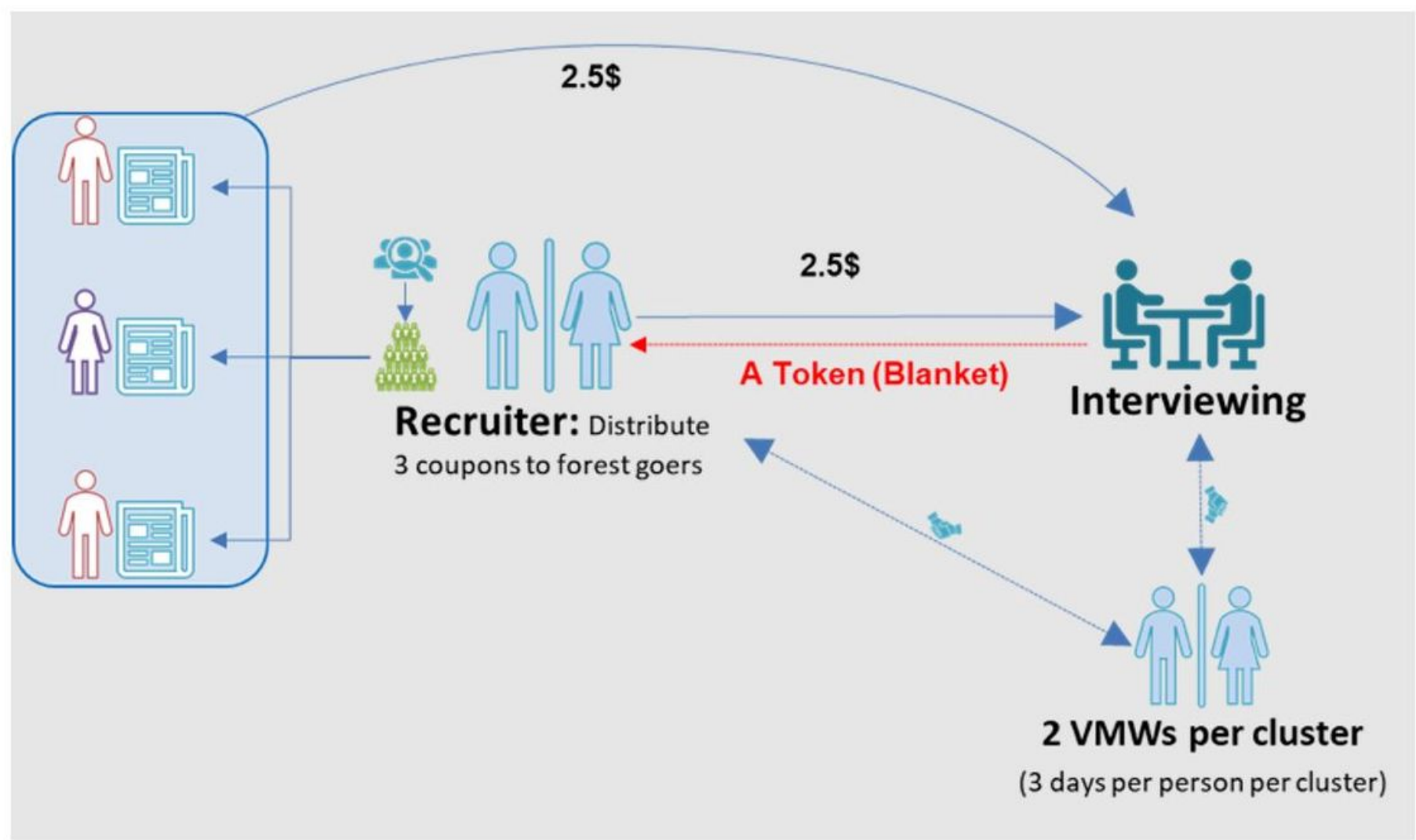

Figure 1

Recruitment and interviewing process 